\title{
The Effectiveness of Religious Psychological Counseling Based Program in Reducing Psychological Stress among Mothers of Disabled Children
}

\author{
Yahya Al-Qatawneh ${ }^{1} \&$ Saleh Al-Khawaldeh ${ }^{1}$ \\ ${ }^{1}$ Faculty of Educational Sciences, The World Islamic Sciences and Education University, Jordan \\ Correspondence: Yahya Al-Qatawneh, Faculty of Educational Sciences, The World Islamic Sciences and \\ Education University, Jordan. E-mail: q_yahya2008@yahoo.com
}

Received: Nov. 27, 2018

doi:10.5539/mas.v13n2p30
Accepted: Dec. 10, 2018

Online Published: January 3, 2019

URL: https://doi.org/10.5539/mas.v13n2p30

\begin{abstract}
The study aimed at investigating the effectiveness of a religious psychological counseling based program in reducing the level of psychological stress of a sample of mothers of disabled children. The sample was intentionally chosen from Al Amal Center for Multi- Disabilities. The sample of this study was assigned randomly into two groups: an experimental group which consisted of (15) mothers who received the training program and a control group which consisted of (15) mothers who did not receive the training program. The researcher administered a pre -post scale on both groups before and after the implementation of the training program to test hypotheses of the study and calculate means, standard deviations, MANOVA and ANCOVA. The results revealed significant differences between the means of the two groups (experimental and control) in favor of the experimental group. Such results were evidenced through a two -month follow up that followed the training program. The study recommended conducting further research on the impact of religious counseling in reducing psychological stress.
\end{abstract}

Keywords: religious counseling, training program, mothers of disabled children mothers, psychological

\section{Introduction}

Psychological stress is a phenomenon of human life that is experienced and lived by individuals throughout their lives and at different levels in different situations and times. The frequent exposure to much of this stress may turn their lives into real suffering, causing many physical and psychological disorders. The recent global statistics indicate that psychological stress causes almost $80 \%$ of the diseases of our age such as heart attack, bloody ulcers, blood pressure, etc. Moreover, it is considered the cornerstone of the occurrence of psychosomatic disorders, and that excessive exposure to stress results in hormonal imbalances, and causes physical, mental, behavioral and emotional diseases (Janourou, 2011; Shekhani, 2003).

Despite the variety and diversity of sources of psychological stress, the moment of discovering a child's disability in the family is a decisive stage that has a direct impact on the psychological, social, behavioral, emotional dimensions and the emotional dimension of the child himself and the rest of the family, but to varying degrees (Sabah and Mansouri, 2013). Because the mother is closer to the child in the family, and more affected by disability, she is the most concerned and anxious members of the family. She always attends and satisfies the child's daily needs, making her live under high psychological stress of multiple sources (Zembat and Yildiz, 2010; Davis, 2009; Graungaard and Skov, 2006; Al-Matar, 2007; Al-Rihani, Zeriqat and Tanous, 2010).

Despite the development of programs and services provided for children with disabilities in recent years, this development did not include adequate provision of services to mothers of these children, which exposed them to many psychological and social problems that caused their high level of psychological stress (Hassan, 2009). This indicates that they are in desperate need of individual psychological assistance or through participation in specialized outreach programs.

In this regard, many researchers and specialists in various fields, especially in the field of psychology, have tried to search for preventive and curative methods and techniques in order to address this psychological phenomenon and mitigate its effects in general. This has resulted in many different theories and therapeutic psychological methods, including psychological religious counseling, which is now presented as one of the proposed therapeutic methods to deal with stress and psychological problems along with other psychological treatment methods. It is a 
method of treatment with specific principles, concepts, foundations, steps and techniques, and is based on the use of religious psychological concepts, such as repentance, patience, optimism and others, with the aim to elevate individuals to a state of compatibility and mental health (Silver Feki and Rajab 2010; hams, 2003; Muzaini, 2005; promises, 2014). This method has been chosen by the researcher in this study.

Because counseling programs based on religious psychological counseling, and because they aim at finding solutions and training individuals to cope with the problem of psychological pressure, it did not find their way to institutions and centers for the care of mothers of children with disabilities. The current study is concerned with the subject of psychological religious counseling and its applications in the counselling programs. The study aims at investigating the effectiveness of a religious psychological counseling-based program to reduce psychological stress among mothers of children with disabilities.

\subsection{Problem and Significance of the Study}

Children with disabilities cause high stress and anxiety in their mothers, and they are more likely to be depressed, have emotional problems and suffer from a high degree of psychological stress. In addition to the child's disability, there are counterproductive results on these mothers as a results of persistent need of the disability and the concern about the future of these children. Many of these mothers, despite this suffering, do not receive any specialized psychological counseling (Al-Matar, 2007; Al-Rihani, Zarqat and Tanous, 2010).

This study tackled the topic of mothers of children with disabilities and focused on designing a training program to reduce their psychological stress. Previous studies, such as AlHour (2017), Yahya (2016), and Fidhah, Al-Faqi and Rajab (2010), have indicated the effectiveness of counseling programs based on religious psychological counseling in reducing psychological stress and disorders and the treatment of their various conditions. Therefore, this study aims to use a comprehensive counseling program to provide the mothers of children with disabilities with the necessary knowledge to help them reconsider their thinking and interaction with others through a program consisting of a group of sessions, containing a variety of exercises.

The significance of this study stems from its purpose of providing information and training, which can benefit the mothers of children with disabilities in the Jordanian society through the counseling programs that handle the use of counseling sessions with mothers of children with disabilities in a scientific and practical way to alleviate the psychological stress they suffer. This could be done by utilizing the components of the program, such as skills and techniques based on scientific basis, and benefiting from the study sample as a group in a way that serves the application of the group-counselling program, and serves members of the group participants. Specifically, this study aims to identify the impact of a counseling program based on religious psychological counseling in reducing psychological stress among mothers of children with disabilities in Jordan.

\subsection{Purpose of the Study}

The present study aimed at designing a training program based on religious psychological counselling and measuring its impact in reducing the psychological stress among a sample of mothers of children with disabilities.

\subsection{Hypotheses of the Study}

1. Are there any statistically significant differences at $(0.05)$ in the post-test in the degree of psychological stress between the experimental and control groups due to the religious psychological counseling -based training program?

2. Are there any statistically significant differences at (0.05) in the post-test (after two months) in the degree of psychological stress between the experimental and control groups due to the religious psychological counseling -based training program?

\subsection{Operational Definition of Terms}

Religious counseling: "Guidance based on religious, spiritual and moral methods, concepts and principles that aim at correcting and changing distorted ideas, dysfunctional perceptions of the individual in all aspects of life, helping him to endure the hardships of life, providing security and self-confidence, peace of mind, and providing a feeling of happiness" (Leahy, 2006, 93). In the current study, it is defined operationally as the group counselling sessions used to inform the mothers of children with disabilities to help them cope with stress.

Psychological stress: "The state of the individual's inability to adapt to the perceived threat, whether real or imagined, of mental, physical, emotional and spiritual health, which produces a series of physiological responses and adaptations (Alzaem and Gillani, 2010). In this study, it is defined as the psychological stress according to the ratios scored by mothers of children with disabilities on the scale of psychological stress developed by Zwawi (1992). 
Mothers of children with disabilities: The mothers of children with disabilities who attend Al Amal Center for Multi- Disabilities during the first semester 2018-2019, whose number are 95, and they represent the population of study.

Limitations of the study:

The study is based on semi-experimental design, on the basis that the independent variable is the religious training program, which seeks to recognize the effectiveness of reducing the psychological stress of mothers of children with disabilities. The results of the study are limited by the method of selection of the sample of the study and the psychometric characteristics of the tool used in the study. It is also limited by the current design of the study, which includes the use of a limited number of participants in the experimental and control groups, as required by the programs of group counseling of a limited number of participants.

\section{Literature Review}

In this section, the researcher tackles some studies and previous research that focused on psychotherapy to reduce psychological stress. The present study- to the researcher's knowledge- is the first study in the Arab environment that seeks to explore the effectiveness of religious psychological treatment program in reducing psychological stress. Previous studies has tackle psychological counseling with many other variables, such as anxiety, depression, psychological adjustment, etc. However, they did not address the provision of a single therapeutic program based on religious psychological counseling to reduce the psychological stress as the present study is attempting to do. The following studies can are useful and related directly to the subject of this study:

The study of Al-Hour (2016), which aimed to investigate the effectiveness of an Islamic psychological counseling program to reduce the symptoms of psychological depression in patients frequently visit the Central Center for Mental Health. The sample of the study consisted of (28) patients divided into two experimental groups (14 patients) and a control group (14 patients). The study found that there were significant differences between the scores of the pre-test and the post-test scores in the psychological depression of the experimental group in favor of the post- test. The study found no statistically significant differences between the post- test and follow-up measures in psychological depression in the experimental group. The study recommended integrating the Islamic religious dimension along with the psychological dimension because of its effective impact in the psychological treatment process.

The study conducted by Yahya (2015) aims at identify the role of religious psychological counseling in achieving psychological compatibility among adolescent girls in high school. The study sample consisted of (152) adolescent girls in secondary school, divided into (76) girls attending Quranic schools, and (76) girls who do not attend Quranic schools, who were chosen using the simple random way. The study found that religious psychological counseling plays a major role in achieving psychological compatibility among adolescent girls, and that there are significant differences in the level of psychological compatibility in favor of adolescent girls who attend with Koranic schools.

Fidah, Qadi and Rajab (2010) conducted a study that aims at exploring the effectiveness of a psychological program based on religious psychotherapy in alleviating the symptoms of obsessive-compulsive disorder in a sample of female university students. The study sample consisted of (20) female university students suffering from obsessive-compulsive disorder. They were divided into two heterogeneous groups: an experimental group of (10) female students and a control group of (10) female students. The results showed the effectiveness of the religious psychotherapy program in alleviating the symptoms of obsessive-compulsive disorder.

The study of Noojin and Wallander (2006) aimed at finding out the effectiveness of an counseling program to reduce depression and the various psychological stress experienced by families of children with different disabilities. The study sample consisted of (85) parents, randomly divided into three groups, two experimental and one control group. The first group received a counseling program based on the modification of cognitive behavior, the second group received a counseling program based on behavior modification, and the third group was a control who did not receive any treatment. The training program included 12 sessions, where discussion techniques, homework training, schedule activities, goals, and relaxation were performed. The results indicated that there were statistically significant differences in favor of members of the first group who received a counseling program based on modifying cognitive behavior, which was supported by follow-up results after six months.

The study of Ghaith, Al-Masry and Mizaghwabian (2011) aimed at verifying the effectiveness of a training program based on cognitive behavioral theory in reducing psychological stress among a sample of mothers of children with meningocele, who were selected intentionally from Al Hussein Association for the Care and Rehabilitation of People with Motor Challenges. The study participants were randomly assigned to the two study 
groups: an experimental group consisting of (15) participants who participated in the training program, and a control group that included (15) participants who were not exposed to the program. The results of the study indicated the effectiveness of the training program applied in reducing psychological stress and the continuation of its effects after one month of the end of the study.

The study of Al-Hams (2005) aimed at investigating the impact of the effectiveness of a psychological counseling program of a religious nature in reducing the symptoms of psychological depression among the wives of the martyrs of Al-Aqsa Intifada. The sample of the survey consisted of (376) wives, where (40) wives were chosen with high degrees of depression. The first experimental group consisted of (10) wives, who have martyred sons, and a second experimental group consisted of (10) wives who do not have martyred sons. The first control group consisted of (10) who have martyred sons, and the second control group consisted of (10) wives who do not have martyred sons. The results of the study showed that there were statistically significant differences after applying the counseling program in favor of the experimental group.

Abu Rumman (2005) conducted an experimental study to identify the effectiveness of a group-counseling program based on cognitive behavioral theory in reducing psychological stress and modifying irrational thoughts in a sample of mothers of disabled children. The sample of the study consisted of (33) mother, who were divided equally into two groups, one experimental group, who received the group counseling program, and another control group who did not receive the program. The results of the study indicated that there are statistically significant differences between the mothers of the experimental and control groups and in favor of the experimental group in reducing psychological stress and improving rational beliefs among the mothers of the experimental group.

Koenig (2002) conducted a study that aimed at identifying the impact of religion as a knowledge scheme in helping people to cope with hardship. The study was applied to a sample of (122) individuals. The study concluded that the trend toward religiosity helps individuals to endure hardship, improves their physical and psychological health and increases the effectiveness of positive social interaction between them.

Sabah and Mansouri (2013) conducted a study that aimed at identifying the impact of psychological stress on the families of the disabled. The sample consisted of (121) families of disabled children. The study found that the families of the disabled suffer from low psychological stress.

A review of related literature shows that the current study is consistent with some previous studies on the effectiveness of a religious-based counseling program on multiple dependent variables, such as the study of AlHour (2015) and Al-Hams (2005), which dealt with the symptoms of depression. The study is also consistent with the study of Yahya (2015), which dealt with psychological compatibility, the study of Fidah, Faqi and Rajab (2010), which dealt with obsessive-compulsive disorder, and with the study of Koenig (2002), which dealt with compatibility with hardship. The current study differs from other previous studies in its focus on psychological stress as a dependent variable. In addition, it dealt with the variable of psychological stress among the mothers of children with disabilities, which distinguishes this study from previous studies. It also differs from some previous studies that used non-religious psychological therapy programs, such as Noojin and Wallander (2006) and Abu Rumman (2005). The current study agreed with these two studies in the dependent variable, reducing psychological stress.

\section{Method and Procedures}

\subsection{The Population of the Study}

The current study population includes all (95) mothers of children with disabilities, who are enrolled in Al-Amal Center for Multi-Disabilities.

\subsection{The Study Sample}

After applying the psychological stress scale on mothers, 30 of them were assigned the highest scores in psychological stress. They were distributed randomly to two groups, one experimental group of (15) mothers and one control group of (15) mothers.

\subsection{Tools of the Study}

Firstly. Psychological Stress Scale: the psychological stress scale developed by Zawawi (1992) was used. The scale consists of (35) paragraphs measuring psychological stress with its three sub-dimensions: physiological, cognitive and psychological, where the total score of the scale was extracted by collecting the scores that constitute levels of psychological stress on the scale. The total score on the scale was between ( 0 and 70$)$, where the score zero represents the minimum, and the maximum score was 70 . The high scores on the scale indicated a high level of psychological stress. Zawawi validated the scale by presenting it to (15) professors of the faculty members of 
the University of Jordan. She calculated the reliability through the internal consistency on a sample of (34) female students using the equation of Cronbach Alfa and the value of reliability was $(0.90)$. To verify the validity of the scale, the researcher validated the scale by presenting it to ten professors, specialists in the field of counseling and special education, and extracted reliability using Cronbach Alpha, and the value of the reliability coefficient was (0.85) on a sample of (30) mothers suffering from psychological stress of members other than the study sample.

The psychological stress scale developed by Zawawi was used to measure the psychological pressures on mothers of children with disabilities, the scale consists of (32) divided into three dimensions, namely:

- Physiological dimension: This factor includes (13) paragraphs: $(1,4,7,10,13,16,19,22,25,28,30$, $32,34)$.

- Cognitive dimension: This factor includes (9) paragraphs: $(2,5,8,11,14,17,20,23,36)$.

- Psychological dimension: This factor includes (10) paragraphs: $(3,6,9,12,15,18,21,24,26,27)$.

Thus, the scale consists of (32) paragraphs, and the answer to each paragraph falls within a scale consisting of three options, namely: ('Never happens', and given one score, 'rarely happens', and given two scores, 'always happens', and given three scores). The scores were calculated in this scale according to Likert scale, where the total score on the scale ranges from (32 - 96), which means that the closer the individual from the maximum score means that the individual suffers from a high degree of psychological stress. The total score on the scale can be extracted by collecting the scores that represent Levels of stress on the scales. The researcher verified the validity of the instrument by calculating the coefficient of consistency using Cronbach's alpha. The stability coefficient for sub-scores was stable as follows: physiological dimension (0.85) cognitive dimension (0.83) and psychological dimension (0.87), respectively. The consistency coefficient of the total score was $(0.91)$ which is acceptable for this study.

Second. The training program: For the purposes of this study, the researcher designed the training program for mothers of children with disabilities. The aim of the program was to train mothers on a range of skills, modeling exercises and applying skills in real life. Accordingly, the program was implemented in 14 sessions, each session lasting 60 minutes. The rationale for the program was presented to a number of specialized arbitrators at Jordanian universities to assess their views on the appropriateness of the program. The following is a brief description of the training sessions included in the training program:

Session 1: (meeting and introduction): the counsellor and mothers introduce each other, setting goals, and developing team spirit.

Session 2: (Participants' Goals): Defining the goals that mothers wish to achieve with the program and developing team spirit and teamwork.

Session 3: (Emotional relief): mothers express freely their difficult feelings and suggest strategies to face future events.

Session 4: (psychological stress): to recognize the concept of psychological stress, its causes, manifestations, and effects, and the formation of a positive trend to reduce such stress using some methods and religious practices.

Session 5: (Roleplay) mothers play the role of a therapist, exchanging roles, providing religious advice to each other, expressing their feelings freely and drawing up procedures that facilitate their interaction with the experiences of others.

Session 6 (patience): Introducing the concept of patience, its ethics and benefits, and alleviate the psychological suffering of mothers using Quranic verses that talk about patience, and turning this knowledge into practice and behavior, as well as keeping up with it.

Session 7 (self-communication): training in the skill of self-communication, and the introduction of the root of the skill of Islamic self-talk to give mothers the ability to be free from the effects of psychological stress.

Session 8 (Relaxation): Developing the ability to free yourself from the effects of stress, confronting situations and anxiety triggers in a realistic manner, and practicing relaxation skills practically.

Session 9 (cultural entertainment activity): Breaking the routine of the sessions and testing their focus on program information, deepening the relationship and friendship among the group members, breaking some maternal convictions, entertaining their emotional side and alleviating their psychological stress.

Session 10 (reciting the Quran): identifying of the importance of reciting the Quran and praising and mentioning Allah, encouraging the use of specific supplications and surahs, distributing papers including a program of home practice and insuring their regular practice to alleviate their psychological suffering. 
Session 11 (Mentioning Allah): Recognizing the importance of mentioning Allah and its benefits, alleviating the psychological suffering of mothers through mentioning Allah, translating knowledge into work by practicing mentioning Allah, and alleviating the psychological suffering of the participants.

Session 12 (Du'aa/ supplication): recognizing of the importance of supplication and its virtues, converting this knowledge into to work by practicing supplication and daily supplications, and giving them the opportunity to taste their psychological benefits.

Session 13 (performing prayers): recognizing the importance of prayer, its benefits and virtues, and the alleviation of psychological stress among mothers by performing and preserving Sunnah prayers.

Session 14 (evaluation of the program): Evaluating the program by mothers, identifying the most that they liked, applying the post-test to them, agreeing on a mechanism of communication between the counsellor and the mothers, closing the program and ending it.

\subsection{Procedures of the Study}

In order to determine the impact of a training program based on religious psychological counseling in reducing the psychological stress of mothers of children with disabilities, Al-Amal Center for Multiple Disabilities in the city of Rusaifa in Zarqa Governorate was selected. The mothers of children with disabilities were divided into two groups, experimental and control. The researcher arranged with the Center and one of the supervisors to determine the duration of the implementation, which was the second semester 2019/2018. The researcher conducted the implementation himself, and the role of the supervisor was limited to receive the mothers participating and assembling them in a hall dedicated to this purpose. The meeting was held every Sunday, Tuesday and Thursday, for about four weeks.

\subsection{Study Design and Statistical Processing}

The study used semi-experimental design, using pre and post test and follow-up after two months. In order to analyze the data, the researcher used the following.

1. ANOVA, to answer the first question.

2. Multivariate Analysis (MANOVA) to answer the second question.

\section{Results of the Study}

First: Results related to the first question: The first question was:

Are there any statistically significant differences at $(0.05)$ in the post-test in the degree of psychological stress between the experimental and control groups due to the religious psychological counseling -based training program?

The mean and standard deviations of the performance of the study participants were calculated on the psychological stress scale between the experimental group and the control group as shown in Table (1).

Table 1. Mean scores and standard deviations of the performance of the study sample on the psychological stress scale between the experimental group and the control group due to the training program

\begin{tabular}{lllllll}
\hline \multirow{2}{*}{ Dimension } & Group & No. & $\begin{array}{l}\text { Pre-test } \\
\text { Mean } \\
\text { score }\end{array}$ & $\begin{array}{l}\text { Std. } \\
\text { deviation }\end{array}$ & Mean score & Std. deviation \\
\hline \multirow{3}{*}{ Physiological dimension } & Experimental & 15 & 33.60 & 4.44 & 21.47 & 4.00 \\
& Control & 15 & 32.73 & 3.20 & 30.73 & 3.20 \\
& Total & 30 & 33.17 & 3.82 & 26.10 & 5.90 \\
\multirow{5}{*}{ Cognitive dimension } & Experimental & 15 & 25.33 & 4.32 & 16.53 & 5.10 \\
& Control & 15 & 24.60 & 6.19 & 23.60 & 6.19 \\
& Total & 30 & 24.97 & 5.26 & 20.07 & 6.63 \\
Psychological dimension & Experimental & 15 & 24.73 & 2.05 & 18.60 & 3.16 \\
& Control & 15 & 25.33 & 3.40 & 23.33 & 3.40 \\
Total score & Total & 30 & 25.03 & 2.77 & 20.97 & 4.02 \\
& Experimental & 15 & 83.67 & 6.50 & 56.60 & 8.63 \\
\hline
\end{tabular}




\begin{tabular}{llllll}
\hline Control & 15 & 82.67 & 7.75 & 77.67 & 7.75 \\
Total & 30 & 83.17 & 7.05 & 67.13 & 13.41 \\
\hline
\end{tabular}

Table (1) shows that there are noticed differences in the mean scores of the performance of the participants according to the psychological stress scale between the experimental group and the control group due to the training program. The total score was (56.60) for the experimental group, which is less than the mean score of the performance of the control group, which was (77.67). The mean scores of the experimental in all dimensions of the study were lower than the mean scores of the control group. In order to determine whether the differences between the mean scores were significant at $(\alpha=0.05)$, MANCOVA analysis was applied, and Table (2) shows the results of the analysis.

Table 2. MANCOVA results for the performance of the study sample in the scale of psychological stress between the experimental and control groups due to the training program

\begin{tabular}{|c|c|c|c|c|c|c|}
\hline Source & Dimension & Sum of sq & & Mean square & F value & Sig. \\
\hline \multirow{4}{*}{ Pre-test } & $\begin{array}{l}\text { Physiological } \\
\text { dimension }\end{array}$ & 58.702 & 1 & 58.702 & 5.147 & 0.032 \\
\hline & $\begin{array}{l}\text { Cognitive } \\
\text { dimension }\end{array}$ & 350.541 & 1 & 350.541 & 17.246 & 0.000 \\
\hline & $\begin{array}{l}\text { Psychological } \\
\text { dimension }\end{array}$ & 29.238 & 1 & 29.238 & 2.906 & 0.100 \\
\hline & Total score & 1010.71 & 1 & 1010.71 & 31.215 & 0.000 \\
\hline \multirow{4}{*}{$\begin{array}{l}\text { Training } \\
\text { program }\end{array}$} & $\begin{array}{l}\text { Physiological } \\
\text { dimension }\end{array}$ & 668.975 & 1 & 668.975 & 58.651 & 0.000 \\
\hline & $\begin{array}{l}\text { Cognitive } \\
\text { dimension }\end{array}$ & 426.568 & 1 & 426.568 & 20.987 & 0.000 \\
\hline & $\begin{array}{l}\text { Psychological } \\
\text { dimension }\end{array}$ & 177.401 & 1 & 177.401 & 17.629 & 0.000 \\
\hline & Total score & 3580.497 & 1 & 3580.497 & 110.582 & 0.000 \\
\hline \multirow{4}{*}{ Error } & $\begin{array}{l}\text { Physiological } \\
\text { dimension }\end{array}$ & 307.965 & 27 & 11.406 & & \\
\hline & $\begin{array}{l}\text { Cognitive } \\
\text { dimension }\end{array}$ & 548.792 & 27 & 20.326 & & \\
\hline & $\begin{array}{l}\text { Psychological } \\
\text { dimension }\end{array}$ & 271.695 & 27 & 10.063 & & \\
\hline & Total score & 874.223 & 27 & 32.379 & & \\
\hline \multirow{4}{*}{ Total } & $\begin{array}{l}\text { Physiological } \\
\text { dimension }\end{array}$ & & & & & \\
\hline & $\begin{array}{l}\text { Cognitive } \\
\text { dimension }\end{array}$ & & & & & \\
\hline & $\begin{array}{l}\text { Psychological } \\
\text { dimension }\end{array}$ & & & & & \\
\hline & Total score & & & & & \\
\hline
\end{tabular}

Table (2) shows that (F) value for the total score on the stress scale between the experimental group and the control group due to the training program was (110.582) and at a significance level of (0.000), indicating that there are statistically significant differences between the mean scores of the performance of the two groups due to the training program. (F) value for the physiological dimension was (58.651), with a level of significance of $(0.000)$. The (F) value for the cognitive dimension was (20.987), and at a level of significance of (0.000), and (F) value for the psychological dimension was (17.629), and at a level of significance of (0.000). This indicates the existence of statistically significant differences between the mean scores of the two groups on the psychological stress scale between the experimental group and the control group due to the variable of the training program in all dimensions. 
This result is rejected by the first zero hypothesis which stated that " there are no statistical significant differences in the degree of psychological stress between the experimental group whose members received the proposed training program to reduce the psychological stress, and the control group, whose members did not receive the proposed training program due to the variable of the psychological stress in the post-test".

In order to know which group the difference was in favor, the adjusted mean scores for the performance of the two study groups in the psychological stress scale were extracted between the experimental group and the control group according to the post-training program. Table (3) shows these results.

Table 3. Adjusted mean scores and standard errors for the performance of the study sample in the psychological stress scale between the experimental and control groups according to the training program

\begin{tabular}{llll}
\hline \multirow{2}{*}{ Dimension } & Group & Adjusted mean score & Std. error \\
\hline \multirow{3}{*}{ Physiological dimension } & Experimental & 21.37 & 0.87 \\
& Control & 30.84 & 0.87 \\
Cognitive dimension & Experimental & 16.29 & 1.17 \\
& Control & 23.85 & 1.17 \\
Psychological dimension & Experimental & 18.53 & 0.82 \\
\multirow{2}{*}{ Post-total score } & Control & 23.41 & 0.82 \\
& Experimental & 56.18 & 1.47 \\
\hline
\end{tabular}

Table (3) indicates that the mean scores of the experimental group members, who received the training program was the lowest (56.18). The mean scores of the members of the control group was 78.09 , which means that the difference was in favor of the experimental group, evidenced by the lowest means they scored compared to the mean scores of the control group in the total scores and in all dimensions. This indicates that the training program had an effect on reducing the stress level of the experimental group members

Second: Results related to the second question: The second question was:

Are there any statistically significant differences at (0.05) in the post-test (after two months) in the degree of psychological stress between the experimental and control groups due to the religious psychological counseling based training program?

The mean and standard deviations of the performance of the study sample were calculated on the psychological stress scale between the experimental group and the control group. Table (4) shows the results.

Table 4. Mean scores and standard deviations of the performance of the study sample in the psychological stress scale and the follow-up measure between the experimental group and the control group according to the training program

\begin{tabular}{lllllll}
\hline \multirow{2}{*}{ Dimension } & Group & No. & $\begin{array}{l}\text { Pre-test } \\
\text { Mean } \\
\text { score }\end{array}$ & $\begin{array}{l}\text { Std. } \\
\text { deviation }\end{array}$ & Mean score & Std. deviation \\
\hline \multirow{3}{*}{ Physiological dimension } & Experimental & 15 & 21.47 & 4.00 & 22.60 & 4.44 \\
& Control & 15 & 30.73 & 3.20 & 34.33 & 3.60 \\
& Total & 30 & 26.10 & 5.90 & 28.47 & 7.17 \\
\hline \multirow{3}{*}{ Cognitive dimension } & Experimental & 15 & 16.53 & 5.10 & 17.33 & 4.32 \\
& Control & 15 & 23.60 & 6.19 & 27.20 & 6.28 \\
& Total & 30 & 20.07 & 6.63 & 22.27 & 7.30 \\
\hline \multirow{2}{*}{ Psychological dimension } & Experimental & 15 & 18.60 & 3.16 & 19.73 & 2.05 \\
& Control & 15 & 23.33 & 3.40 & 26.93 & 3.28
\end{tabular}




\begin{tabular}{lllllll} 
& Total & 30 & 20.97 & 4.02 & 23.33 & 4.54 \\
\hline \multirow{3}{*}{ Total score } & Experimental & 15 & 56.60 & 8.63 & 59.67 & 6.50 \\
& Control & 15 & 77.67 & 7.75 & 88.47 & 8.35 \\
& Total & 30 & 67.13 & 13.41 & 74.07 & 16.39 \\
\hline
\end{tabular}

Table (4) shows that there are apparent differences between the mean scores of the performance of the participants in the psychological stress scale between the experimental group and the control group due to the training program. The total score was (59.67) for the experimental group, which is less than the mean scores of the performance of the control group (88.47). The mean scores of the experimental group in all dimensions of the study were lower than the control group's scores. To determine whether the differences between the mean scores were significant at $(\alpha=0.05)$, MANOVA was applied, and Table (5) shows the results of the analysis.

Table 5. The results of MANOVA analysis of the performance of the participants in the psychological stress scale and the follow-up measure between the experimental group and the control group due to the training program

\begin{tabular}{lllllll}
\hline Source & Dimension & Sum of squares & df & Mean square & F value & Sig. \\
\hline \multirow{2}{*}{ Training } & Physiological dimension & 1032.533 & 1 & 1032.533 & 63.272 & 0.000 \\
program & Cognitive dimension & 730.133 & 1 & 730.133 & 25.123 & 0.000 \\
& Psychological dimension & 388.8 & 1 & 388.8 & 51.873 & 0.000 \\
& Total score & 6220.8 & 1 & 6220.8 & 111.152 & 0.000 \\
\hline \multirow{5}{*}{ Error } & Physiological dimension & 456.933 & 28 & 16.319 & & \\
& Cognitive dimension & 813.733 & 28 & 29.062 & & \\
& Psychological dimension & 209.867 & 28 & 7.495 & & \\
& Total score & 1567.067 & 28 & 55.967 & & \\
\multirow{5}{*}{ Total } & Physiological dimension & 1489.467 & 29 & & & \\
& Cognitive dimension & 1543.867 & 29 & & & \\
& Psychological dimension & 598.667 & 29 & & & \\
& Total score & 7787.867 & 29 & & & \\
\hline
\end{tabular}

Table (5) shows that (F) value for the total score in the psychological stress scale and follow-up measure between the experimental group and the control group due to the training program was $(111,152)$ and at the significance level (0.000), indicating that there are statistically significant differences between the mean score of the performance of the groups of the study due to the training program. (F) value for the physiological dimension was (63.272), with a significance level of (0.000). (F) value for the cognitive dimension was (25.123), with a significance level of (0.000), and the psychological dimension was (51.873), with a significance level of $(0.000)$. This indicates that there were statistically significant differences between the mean scores of the performance of the two groups in the psychological stress scale between the experimental group and the control group due to the variable of the training program in all dimensions. With this result, the second zero hypothesis was rejected, which stated that "there are no statistically significant differences in the scores of psychological stress between the experimental group, whose members received the proposed training program to reduce the psychological pressure, and the control group, whose members did not receive the proposed training program, on the variable of psychological stress in follow up measure after three months."

Table (5) shows that the difference was in favor of the experimental group, who received the training program, where their mean score was the lowest (59.67), while the mean scores of the control group was (88.47). This indicates that the training program had an impact on reducing the level of stress among the experimental group in the follow-up after measure three months.

\subsection{Discussion of Results}

The findings of this study supported the effectiveness of the religious counseling program in reducing the psychological stress of mothers of children with disabilities and the sustainability of the therapeutic program beyond the follow-up period. This may be attributed to: 
1. The training program considered the principles and standards of religious psychological counselling, especially in the stage of building the therapeutic relationship, urging active participation, helping mothers to understand the philosophy of suffering, its meaning, and its alleviation. Moreover, the program helped in benefiting from the religious aspect of being a Muslim, who believe in the Quran and Sunna, and in their urging for patience at times of hardship. Having a disabled child in the family is a kind of tribulation to test the patience of the faithful. The program also helped in understanding how to address the self from te Islamic perspective, and here reflects the spiritual capacity of the mother to absorb the lesson.

2. The program benefited from the individualization of religious psychological counselling and its multilayers, which helped the mothers to improve in a case-by-case framework and in accordance with their individual situation. Each mother participated in the training that was assigned to her and according to the technical aspect that suits her alone, which is and advantages of Psychotherapy.

3. The program depended on explaining each technique before starting it, specifying the outline of each session, forming a discussion with the mother, presenting a summary of each session; sometimes written and sometimes orally, and in practice in other times. Moving to another point was done after making sure they understand and apply each point and operational objective. The program started by persuading mothers of the importance, principles and feasibility of treatment, urging them to pay attention and follow-up carefully to it. The human nature, especially women, inclined to what is new and useful, especially that they did not receive this kind of guidance. The program was a new trend; they found in it a real relief that expressed their true suffering honestly. They competed to present their suffering, and became proud of having the ability to overcome hardship more than others.

4. The program depended on scheduling activities and assignments carried out by the mother in the session and outside periodically in the implementation of the session, which is emphasized for its importance in any religious psychological counselling program.

As for the continuity of the effectiveness of the therapeutic program used, it was confirmed by checking with the continued improvement in the skills of mothers to overcome stress and reduce the performance of therapeutic techniques periodically after the follow-up period, which may be due to:

1. The religious psychological counselling came in touch with the essence of human life and has an important role in building the mental health of the individual, through which pressure can be overcome, because we do not have any shelter nor escape from Allah Almighty except to flee to him. We all look for what helps us to ease the worldly hardships that become a burden on our shoulders. Therefore, the mothers have maintained what they have trained in the sessions, and made sure that such training becomes a part of their mental and spiritual formation.

2. The reinforcement and home assignments during each session had the obvious effect of supporting and encouraging mothers, as members of an organized group, to play various roles, to play these roles in life through the family at home, and through their acquaintance in society. Therefore, self-strength have been instilled in each mother, and they have been taught that they are stronger than the psychological stress, and that Man is the best creatures of all, and has a strong psychological energy, drawn from closeness, attachment and appeal to Allah Almighty. Moreover, the individual should not allow psychological stress to take over him/her, and that he/she are able to prevent and respond to it if trained on a variety of ways to fight it. Sometimes a person can use ideas, discussion, and debate to fight it, and sometimes a person can use asking Allah for forgiveness for its certain effects and supported to cope with psychological disorders.

Therefore, implementing the program has achieved one of its main objectives, which is to modify stressful ideas in general. The purpose of conducing behavioral modification programs is not to make temporary changes in the temporary different aspects of personality, which is soon to be faded as if nothing happened, but rather what is required in these programs is the persistence and continuation of the impact even after ending the training that the mothers received during the sessions of this program, and even after the losing contact with the responsible personals of the training. One of the essential matters in implementing those programs is to ensure their continuity and effectiveness among the members of the experimental group after the end of the sessions of the program. Eventually, this adds confidence that the mothers have used the different strategies they have learned in their life situations without resorting to a psychological therapist. In addition, it also gives justification to try to apply these programs to large segments of mothers, especially those who suffer from stress, distress and hardship due to constant psychological stress, and the accompanying poor social harmony and many other psychological problems. 
Therefore, the results of this study was consistent with the results of the studies of Koenig (2002), Al-Hams (2002), Yahya (2015), and Noojin and Wallander (2006), all of which indicated that the mothers of children with disabilities suffer from psychological stress, and that the training programs provided to them were effective in reducing their psychological stress and proved their continuity after follow-up. The current study disagreed with the study of Sabah and Mansouri (2013), which concluded that the families of the disabled suffer from low psychological pressure.

\section{Recommendations}

Based on the results of this study, the researcher recommends the following:

1. Conducting more experimental studies to examine the effectiveness of religious psychological counselling-based programs, in the framework of marriage counselling that includes both spouses.

2. Conducting further studies to examine the effectiveness of religious psychological counselling-based programs on variables related to the mental health of parents and siblings of children with disabilities, and for a longer follow-up period after the end of the program to examine the continuity of the results obtained.

3. Using the religious counselling program prepared in this study with mothers of children with disabilities who have high psychological stress.

\section{References}

Abu Rumman, F. (2005). The Effectiveness of a Group Counseling Program in Reducing Psychological Stress and Modifying Irrational Ideas among the Mothers of Children with Special Needs in Amman, Unpublished Master Thesis, Hashemite University, Jordan.

Al-Homs, A. (2005). The Effectiveness of a Counselling Program in Reducing the Symptoms of Psychiatric Depression among the Wives of Martyrs of Al-Aqsa Intifada, unpublished PhD thesis, Al-Aqsa University, Gaza.

Al-Hour. A. (2016). Effectiveness of an Islamic Counselling Program to Reduce Psychological Depression. Unpublished Master Thesis, Islamic University, Gaza.

Al-Matar. F. (2007). The concept of self in children with chronic anemia, stress and coping methods among people with special needs and their parents in the Eastern Region of Saudi Arabia (survey). Unpublished $\mathrm{PhD}$ thesis, University of Jordan, Amman, Jordan.

Al-Muzaini. O. (2001). Religious Values and its Relation to Emotional Balance and Levels, Unpublished Master Thesis, Department of Psychology, Islamic University, Palestine.

Al-Rihani, S., Al-Zureikat, I., \& Tanus, A (2010). Counselling Persons with Disabilities and their Families. ed 1, Dar Al-Fikr, Amman, Jordan.

Alzaem, A., Sulaim, S., \& Gillani, S. (2010). Assessment of the validity and reliability for a newly developed stress in academic life scale (SALS) for pharmacy undergraduates. International Journal of collaborative Research on Internal Medicine and Public Health, 2(7). 239-256.

Bawood, A. (2014). Psychotherapy for Psychological Disorders from an Islamic Perspective: Depression as a Model. Journal of Social Sciences, 19, 199-209.

Davis, K. (2009). The impact of child family and professional support characteristics on the quality of life in families of young children with disability. Journal of Intellectual and Developmental Disability, 34(2), 153162.

Fidah. H, Waqfi, A., \& Rajab. S. (2010). The Effectiveness of Religious Psychotherapy in Relieving the Symptoms of Obsessive-Compulsive Disorder in a Sample of University Students. The Higher Education Seminar for the girl: dimensions and aspirations from 4 to 6 January. Taibah University, Saudi Arabia, 461424.

Ghaith, S., Al-Masri, A., \& Mizagubian, A. (2011). The Effectiveness of a Cognitive Behavioral Training Program in Reducing Psychological Stress among Mothers of Children with Meningoids. Journal of Educational Sciences, 7(4), 303.

Graungaard, A., \& Skov, L. (2006). Why do we need a diagnosis? A qualitative study of parent's experiences, coping and needs, when the new born child is severely disabled. Child: Care, Health and Development, 33(3), 296-30. 
Janourou, Z. (2011). Psychological stress and its relation to the five personality factors of students in Syria and Algeria, Master Thesis, University of Algiers, Algeria.

Koenig, H. (2002). Religion as cognitive schema. International Journal for the psychology of Religion, 1(5). 31-37.

Leahy, R. (2006). A detailed practical guide to the practice of cognitive psychotherapy in mental disorders. translated by Jum'a Yousef and Mohamed El-Sabwa. Cairo: Itrak For Printing, Distribution and Distribution (Translated, 2006).

Muna, H. (2009). Psychological stress and its relation to the needs of parents of the disabled (handicapped) in the state of Khartoum, Master Thesis published, Department of Psychology, University of Khartoum, Sudan.

Noojin, A., \& Wallander, J. (2006). Perceived problem-solving ability, stress, and coping in mothers of children with physical disabilities: potential cognitive influences on adjustment. International of Journal of Behavioral Medicine, (4). 415-482.

Sabah, A., \& Mansouri, A, (2013). Psychological Pressure among Families of the Disabled, Journal of Psychological and Educational Studies, University of Wahran, (11), 199-224.

Sheikani. Y. (2003). Psychological Stress (its nature, causes, self-help, and healing), ed (1), Dar al-Fikr, Beirut, Lebanon.

Yahya, A. (2015). The Role of Religious Psychological Counseling in Achieving Psychological Compatibility among Adolescent Girls in Secondary School. Unpublished Master Thesis, Mohammed Boudiaf University, Algeria.

Zawawi, R. (1992). The Effect of Group Counselling on Problem Solving Training in Stress Reduction, Unpublished Master Thesis, University of Jordan, Amman.

Zembat, R., \& Yildiz, D. (2010). A comparison of acceptance and hopelessness levels of disabled preschool children's mothers. Social and Behavioral Sciences, (2), 1457-1461.

\section{Copyrights}

Copyright for this article is retained by the author(s), with first publication rights granted to the journal.

This is an open-access article distributed under the terms and conditions of the Creative Commons Attribution license (http://creativecommons.org/licenses/by/4.0/). 